\title{
Las revistas especializadas y la calidad de la investigación en enseñanza de las ciencias
}

La investigación en la enseñanza de las ciencias ya tiene en el nivel internacional lo que Stephen Toulmin denomina foro institucional. Ya contamos con una comunidad de investigadores que tiene sus asociaciones, congresos, cursos de posgrado y otros constituyentes de ese foro. Todos esos factores son importantes y han contribuido a la creación y consolidación del área de investigación en enseñanza de las ciencias. Sin embargo, las revistas especializadas son el filtro más importante. Así es en las ciencias de donde venimos, y en otras disciplinas en las cuales buscamos aportaciones.

En este aspecto, el de las revistas especializadas, vamos bien en términos de cantidad. Ya tenemos un buen número de revistas y la publicación electrónica nos abre un sinnúmero de puertas. No obstante, en términos de calidad todavía hay mucho que hacer, tanto en lo que se refiere al proceso editorial como en lo que tiene que ver con el material resultante de las investigaciones.

Desde los investigadores, las críticas son particularmente en el sentido de que: 1) los trabajos tardan mucho en salir, y 2) los criterios de aceptación no son muy claros: a veces un buen trabajo es rechazado y otro de menos calidad es publicado.

Para los editores, los problemas que identifican para mantener la periodicidad, la calidad y la transparencia de criterios son, principalmente: 1) los árbitros tardan mucho en contestar; 2) las evaluaciones son muy débiles y poco constructivas; 3) el apoyo logístico/administrativo es, frecuentemente, muy pequeño; 4) la calidad de los trabajos que reciben es, muchas veces, baja.

Por otro lado, los investigadores, los editores y los árbitros somos nosotros. Es decir, la calidad de nuestras revistas que, a su vez, constituyen el más importante criterio de calidad de nuestra área, depende exclusivamente de nosotros mismos, los que conformamos la comunidad de investigación en enseñanza de las ciencias. 
Consecuentemente, si es que queremos que nuestra investigación y nuestras revistas especializadas tengan, de hecho, el reconocimiento que todos esperamos dentro y fuera de la comunidad, los siguientes cuidados o recomendaciones son esenciales:

- Mejorar la calidad de las investigaciones en términos de relevancia de las cuestiones-foco y de fundamentación teórica, metodológica y epistemológica, teniendo siempre en cuenta el contenido científico.

- Generar líneas de trabajo progresivas, conducidas por grupos de investigación.

- Distinguir entre investigación e innovación, entre investigación y reflexión, entre investigación y relato de experiencia.

- Reconstruir las aportaciones externas en términos de las contribuciones que pueden tener respecto a la especificidad de la investigación en ciencias; evitar el aplicacionismo.

- Mejorar el proceso de evaluación de trabajos por pares; explicitar criterios propios del área; estimular la evaluación crítica; formar evaluadores.

- Tener en cuenta que las publicaciones en las revistas son las más reconocidas.

- Evitar la multiplicidad injustificada de autores; no firmar artículos sin efectiva participación; no someter (mucho menos publicar) el mismo trabajo en dos revistas; no maquillar trabajos ya presentados en congresos.

Editorialista Invitado

Profesor Doctor Marco Antonio Moreira Instituto de Física. Universidad Federal de Río Grande del Sur (Brasil) 